\title{
A MATEMÁTICA E O DESINTERESSE DOS ALUNOS NA ESCOLA ATUAL
}

\section{MATHEMATICS AND DISINTEREST OF STUDENTS IN CURRENT SCHOOL}

\section{MATEMÁTICAS Y DESINTERES DE ESTUDIANTES EN LA ESCUELA ACTUAL}

\author{
Carlos Bruno Cândido da Silva
}

Roseana Cavalcanti da Cunha ${ }^{2}$

1. Mestre. Professor da Rede Pública Estadual do Estado de Pernambuco.

2. Doutora. Professora da Pós-Graduação e da Graduação do Centro Universitário UNIFACISA-FCM-Campina Grande-PB

RESUMO: A matemática por si só representa um papel fundamental na vida das pessoas, contribuindo para resolução de problemas, aplicações em trabalho, além de funcionar como instrumento para a construção de conhecimentos em outras áreas curriculares. Interfere também, na formação de capacidade intelectual, na estruturação do pensamento e na agilidade do raciocínio dedutivo do aluno. Neste sentido, o presente estudo objetivou analisar as dificuldades de aprendizagem na disciplina matemática no ensino médio. Levantando alguns dados que ajudem a entender o desinteresse pela matemática e identificar os motivos da reprovação em matemática. Assim, realizou-se uma pesquisa com os alunos, não sendo necessária sua identificação, a fim de esclarecer e compreender melhor algumas informações que foram coletadas. Observa-se que, alguns docentes relatam a falta de espaço físico próprio para a realização das atividades, a ausência de reagentes e materiais necessários, e uma deficitária preparação para este tipo de atividade como sendo os principais problemas para o aspecto citado. Portanto, o professor deve estar consciente da necessidade de estar com suas aulas sempre bem planejadas. Este planejamento irá deixá-lo com mais segurança e em condições de debater com seus alunos sobre o conteúdo desenvolvido, buscando um engajamento de todos na busca do conhecimento.

Palavras-chave: Construção de Conhecimentos. Docentes. Planejamento Escolar.

\begin{abstract}
The math itself is a key role in people's lives, contributing to problem solving, applications work, and work as a tool for building knowledge in other curricular areas. It interferes also in the formation of intellectual capacity, the structuring of thought and streamlining the deductive reasoning of the student. In this sense, the present study aimed to analyze the learning difficulties in mathematics discipline in high school. Raising some data to help understand the lack of interest in mathematics and identify math disapproval of reasons. Thus, a survey was conducted with students, there is no need identification in order to clarify and better understand some information that was collected. It is observed that some teachers report a lack of physical space itself to carry out the activities, the absence of necessary reagents and materials, and a deficit preparation for this type of activity as the main problems for the aspect mentioned. Therefore, the teacher must be aware of the need to be with their classes always thoughtful. This planning will leave you with more security and able to discuss with their students about the content developed, seeking a commitment from everyone in the pursuit of knowledge.
\end{abstract}

Keywords: Knowledge Construction, Teachers, School Planning.
RESÚMEN: La matemática por sí sola juega un papel fundamental en la vida de las personas, contribuyendo a la resolución de problemas, aplicaciones de trabajo, además de funcionar como un instrumento para construir conocimiento en otras áreas curriculares. También interfiere en la formación de la capacidad intelectual, en la estructuración del pensamiento y en la agilidad del razonamiento deductivo del alumno. En este sentido, el presente estudio tuvo como objetivo analizar las dificultades de aprendizaje en matemáticas en la escuela secundaria. Levantar algunos datos para ayudar a comprender la falta de interés en las matemáticas e identificar las razones del fracaso en las matemáticas. Por lo tanto, se realizó una encuesta con los estudiantes, sin identificación necesaria, para aclarar y comprender mejor cierta información que se recopiló. Se observa que algunos maestros informan que la falta de espacio físico adecuado para llevar a cabo las actividades, la ausencia de reactivos y materiales necesarios, y una preparación deficiente para este tipo de actividad son los principales problemas para el aspecto mencionado. Por lo tanto, el maestro debe ser consciente de la necesidad de tener sus clases siempre bien planificadas. Esta planificación lo dejará con más seguridad y en condiciones de debatir con sus estudiantes sobre el contenido desarrollado, buscando la participación de todos en la búsqueda de conocimiento.

Palabras clave: Construcción del conocimiento. Maestros Planificación escolar. 


\section{Introdução}

Nas últimas décadas o ensino da Matemática sofreu mudanças significativas, desde sua metodologia até suas ideias primitivas, mas apesar dos esforços no sentido de propor mudanças no ensino da Matemática nos últimos anos, esta disciplina continua sendo considerada a grande vilã dentre as áreas do conhecimento, responsável pelos altos índices de reprovação dos alunos. Os alunos apresentam dificuldade de aprendizagem em todas as disciplinas, porém a matéria mais criticada e questionada é a matemática.

A matemática apresenta papel importante na vida das pessoas, contribuindo para resolução de problemas do cotidiano, aplicações em trabalho, além de funcionar como instrumento para a construção de conhecimentos em outras áreas curriculares. Interfere ainda na formação de capacidade intelectual, na estruturação do pensamento e na agilidade do raciocínio dedutivo do aluno. Além de causar duas sensações contraditórias, uma, por parte de quem ensina a constatação de que se trata de uma área de conhecimento importante. A outra, do lado de quem aprende a insatisfação diante dos resultados negativos obtidos frequentemente, baseado nos PCN's (Parâmetros Curriculares Nacionais) - Ensino Fundamental (BRASIL, 1997).

Se a matemática é tão importante, por que as pessoas não gostam? Um dos pontos será porque ela tem sido pensada e tratada por profissionais que trabalham fora da realidade do aluno? Além dos professores encontrarem em sala diversos obstáculos, será um dos principais a falta de motivação dos alunos? Ou será a falta de estimulo do próprio professor?

$\mathrm{Na}$ maioria das vezes, o professor que leciona matemática escuta, tanto de alunos como de professores de outras áreas, a dificuldade de se aprender ou lecionar matemática. Com esta perspectiva do questionamento, este estudo tenta descobrir os verdadeiros motivos para tal circunstância. As expressões utilizadas na sala de aula pelos alunos "afe!!! aula de matemática", "gosto do senhor professor, mais da matéria!" entre outras, trouxe inquietação, enquanto professor de Matemática, com relação aos desinteresses apresentados pelos alunos com a Matemática. Outro aspecto preocupante que está estritamente lidado ao desinteresse apresentado é o fato da metodologia usada pelos professores, contribuir para que os alunos afirmem "detestar" a matemática.

Com essas argumentações, objetiva-se analisar as dificuldades de aprendizagem na disciplina matemática no ensino médio. Levantando alguns dados que ajudem a entender o desinteresse pela matemática e identificar os motivos da reprovação em matemática.

Os alunos acham que a matemática é um corpo de conceitos verdadeiros e estáticos, do qual não se dúvida ou questiona, nem mesmo nos preocupamos em compreender porque 
funciona. Em geral, acreditam também, que esses conceitos foram descobertos ou criados por gênios (D’AMBROSIO, 1986).

Vale frisar que o referido estudo considerou que quem tem papel importante nesse processo, não é só o aluno e professor, mas também a família, por isso é necessária que ela esteja presente na vida escolar do aluno. Ou seja, a família precisa trabalhar em parceria com escola e aluno, dividindo a responsabilidade com a escola. Com êxito, o aluno ao elaborar seu próprio conhecimento, necessita do professor apenas para fazer a mediação desse intercâmbio. Sendo assim é essencial fazer uma avaliação no momento de diagnosticar as dificuldades de aprendizagem, chegando a uma hipótese diagnostica e não a uma conclusão decisiva, antes de avaliar todos os processos que interagem na vida do aluno. Os autores utilizados como base teórica Dockrell e Mcshane (2000), Parra (1996), Lima (1997), Dante (1989), Lorenzato (2006), Sadovsky (2007), Santos (2003), Miguel e Miorim (2011), que dedicaram à área da didática da matemática.

Com a dificuldade de aprendizagem, cabe ao professor refletir sobre a sua metodologia de ensino, buscando fazer uma relação entre o tema exposto com o assunto entendido pelo aluno, e conscientiza-los da importância do mesmo na vida profissional. A metodologia utilizada deve contribuir para que os alunos sejam inseridos no contexto social, além da motivação para que a aprendizagem seja atraente, e assim prender a atenção dos alunos (MIGUEL; MIORIM, 2011).

Assim afirmamos, por entendermos que o corpo discente se destaca pela curiosidade, de ser valorizado, ter importância, além de ter vontade de aprender, cabendo, portanto, aos professores sempre incentivar os alunos, levantando sua autoestima, não o repreendendo publicamente, nem constrangendo os alunos, onde ninguém gosta de ser reprendido além de ser bastante constrangedor.

A relevância desta pesquisa foi de descobrir o motivo do desinteresse dos alunos na disciplina matemática, e procurar desenvolver métodos, soluções, para motivar os alunos, alterando essa desmotivação, desinteresse.

Procurar sempre novas metodologias e novas formar de buscar o ensino-aprendizagem, as metas serão atingidas, e como principal objetivo a formação de cidadãos competentes e capazes de integrar e contribuir para sociedade. 


\section{Metodologia}

Esta pesquisa foi orientada por uma abordagem qualitativa, buscando compreender a problemática do ensino e aprendizagem que investiga, examinando o próprio contexto em que ocorre. A pesquisa qualitativa, segundo Araújo e Borba (2004), lida e dá atenção às pessoas e aos seus pensamentos, procurando sempre dar sentido aos seus discursos que por muitas vezes não são expostos. Para Godoy (1995, p. 62) retrata a diversidade que há entre os trabalhos qualitativos e destaca várias características essenciais capazes de identificar uma pesquisa. Entre eles: o ambiente natural como fonte direta de dados e o pesquisador como instrumento fundamental, o caráter descritivo, o significado que as pessoas dão às coisas e à sua vida como preocupação do investigador e enfoque indutivo.

Dessa forma, realizou-se uma pesquisa com os alunos, não sendo necessária sua identificação, a fim de esclarecer e compreender melhor algumas informações que foram coletadas. O campo de pesquisa foi composto por 15 alunos do ensino médio, escolhidos aleatoriamente. Com 6 mulheres e 9 homens, pertencentes a diferentes classes sociais. Todos os alunos são do ensino médio, sendo que seis estudam nos primeiros anos, quatro nos segundos anos e cinco nos terceiros anos. Realizada no ano de 2014, em uma escola de rede de ensino estadual, Escola Técnica Estadual Célia de Souza Leão Arraes de Alencar, localiza no município de Bonito-PE.

\section{Resultados e Discussão}

Em relação à média de notas obtidas pelos alunos, há surpresas. Pois a menor média de nota alcançada foi entre 5 e 6, dentre esses três alunos marcaram essa alternativa. Por outro lado, a maior nota marcada por um aluno, situa-se entre 9 e 10. Os demais ficaram entre 6 e 9 em média. Com essa primeira pergunta dá para perceber que a maioria não tem tanta facilidade, mas estão na média, porém não dá para afirmar se os alunos aprenderam o conteúdo.

Segundo Lorenzato (2006, p. 15), "Sabemos que o contexto social no qual a pessoa está inserida influi fortemente em seu modo de pensar e de agir, em seus interesses e necessidades e na hierarquização de seus valores". No ensino da matemática priorizam-se características como: curiosidade, persistência, responsabilidade e espírito colaborativo, para motivar o aluno.

Ainda sobre esse contexto social, Lima (1997), afirma que o ser humano tem muito potencial, e a direção que tomar é influência do meio, das práticas culturais, das instituições e 
das possibilidades de acesso às informações em seu contexto. Com base nestes argumentos entendemos que a escola pode proporcionar condições de interferir no meio em que vive.

Concordamos com Lorenzato e Lima (1997), a respeito da influência do meio no modo de pensar, nas práticas culturais cabendo a escola propor meios de interferir no seu meio, na sociedade que o assiste. No âmbito do ensino da matemática, este meio social deve ser aproveitado para despertar no aluno, durante o processo da aprendizagem a curiosidade, a persistência, a responsabilidade e o espírito colaborativo. Com estes adjetivos acreditamos que os alunos se sentirão motivados e atraídos pelos conteúdos matemáticos.

Em relação à reprovação quando se pergunta, se eles tinham sido reprovados nessa disciplina? Dois alunos responderam que "sim" os demais que "não". Com essa amostra percebemos que bem mais da metade nunca foram reprovados, cerca de $13 \%$ foram reprovados, sendo um índice não muito elevado. Dos dois alunos que foram reprovados, marcaram os motivos, da reprovação, um deles "não compreendia o que o professor expressava", e o outro disse "não se interessava pela matéria, pois acho que ela não tem nada de interessante a lhe oferecer".

Segundo a professora Sadovsky (2007), o baixo rendimento em matemática, não ocorre só no Brasil, onde atualmente a disciplina se restringe em regras mecânicas oferecidas pela escola, que em muito dos casos não se sabe onde usar.

Para Parra (1996), o essencial é decidir a respeito dos conteúdos e a metodologia mais adequada. Essa metodologia é que vai atrair a atenção do aluno, fazendo com que ele tenha afinidade com a disciplina. Pode-se perceber com essa pesquisa que o número de reprovados, em relação aos entrevistados, está diminuindo, apesar dos sujeitos da pesquisa ter sido uma pequena quantidade e pegos aleatórios, mas é perceptível. Além de perceber que os reprovados não são apenas mulheres, quebrando essa mentalidade, ideia, de que a matemática é coisa de homem. Cunha (1993), já afirmava essa teoria, de incentivar a mudança de valores que se tem da matemática, não sendo exclusiva para homens.

Sugere-se a mudança desses conceitos, mostrando a importância da matéria, sua utilização auxiliando na lógica e compreensão no cotidiano. Eixo comum a Parra e Sadovsky (1996), facilmente perceptível, deve-se procurar meios, metodologias que atraia a atenção do aluno, e assim contribui para o aluno ter mais afinidade com a disciplina.

Apenas cinco alunos responderam que o maior índice de reprovação em sua turma está nessa disciplina. Percebe-se que o restante do alunado entrevistado, dez estudantes, responderam não, que a matemática não é responsável pela reprovação em suas salas. Então aos 
poucos, com tantas metas para atingir, os professores estão sempre procurando novos meios para diminuir esse o índice, contribuindo para a diminuição desta rejeição em matemática.

Fator importantíssimo para aumentar a aprendizagem é sem dúvida o professor. O professor como agente motivador no processo de ensino-aprendizagem, pode interferir no planejamento e o desenvolvimento das aulas realizadas como pontos fundamentais, para atender as necessidades de seus alunos, levando em consideração o emocional. Concorda-se com Vygotsky (1991), quando se diz que o pensamento propriamente dito é gerado pela motivação, ou seja, por nossos desejos interesses e emoções.

Os profissionais da área da matemática no campo atual estão capacitados para diminuir esse desinteresse dos alunos pela disciplina, e incentivar os alunos a gostarem da matemática? Na resposta para esta pergunta apenas um aluno, dos entrevistados, respondeu não, consequentemente todos os outros 14 responderam sim. Percebe-se que os alunos enxergam os professores como capacitados, embora não se pode generalizar, pois a pesquisa foi realizada aleatoriamente, podendo interferir na solução, mas com esses alunos entrevistados percebe-se que os professores estão capacitando-se, preparando-se cada vez mais na sua área, e tentando quebrar esse "tabu" da rejeição referente à disciplina.

Apesar dos dados demostrarem que os professores estão capacitados, temos que ter cuidado com esse resultado, pois os alunos entrevistados não dão para generalizar. Como os dados foram aleatórios, isso pode interferir no resultado.

A melhor forma para diminuição do índice de reprovação respondida pela maioria dos entrevistados seria a transformação das aulas com momentos mais interativos. Para os alunos compreenderem a verdadeira importância da matemática, a aula tradicional, torna-se cansativa. Por outro lado, as aulas em que os alunos aprendem brincando, saindo da rotina foram indicados como as mais desejadas. Apenas uma pessoa escolheu a função "mudando a forma de avaliação", de certo modo interligando com aulas interativas, renovando os meios de avaliação, saindo do tradicional, prova e aluno. Onde se pode ter o tradicional, porém não ficar apenas exclusivo desse método arcaico.

Duas pessoas responderam, já que um aluno deixou essa pergunta em branco, diferentes, uma disse que só basta os alunos quererem aprender. $\mathrm{O}$ outro disse que "os alunos deveriam mostrar mais interesse nos estudos, os professores que me ensinaram, sempre foram dinâmicos". Pela visão desse aluno observa-se que grande parte dos alunos não contribui para o desenvolvimento dos estudos, onde sobrecarrega a função do professor. 
Para tanto, professor na busca de novas metodologias para o processo ensinoaprendizagem da matemática pode despertar o interesse pelo estudo, através da dinamicidade.

A juventude se destaca pela sua curiosidade, pela vontade em aprender, de ser importante, cabe a nós sempre incentivá-lo, não o repreendendo, pois ninguém gosta de ser exposto a situações constrangedoras (FILGUEIRAS, 2014).

Concorda-se com Parra (1996), na definição os conteúdos além das metodologias mais convenientes. Lima (1997) em sua contextualização, que afirma que o ser humano tem vários caminhos de desenvolvimento para seguir, sendo esse caminho função do meio em que se vive. Então a escola, em geral, deve oferecer condições aos alunos interferir no meio em que vive.

Outra pergunta da pesquisa foi a seguinte: $\mathrm{O}$ aprendizado e incentivo dos professores de matemática, na visão dos alunos foram considerados suficientes no campo da matemática? Dos 15 alunos, 12 responderam que sim, reforçando mais uma vez, a capacitação dos mesmos, despertando a atenção do corpo discente.

$\mathrm{O}$ aspecto de natureza pedagógica (o espaço físico como os laboratórios, condições dos materiais como vidrarias, reagentes e preparação de professores), é o mais destacado por professores em exercício. Alguns docentes relatam a falta de espaço físico próprio para a realização das atividades, a ausência de reagentes e materiais necessários, e uma deficitária preparação para este tipo de atividade como sendo os principais problemas para o aspecto citado. De forma específica, a falta de preparação do professor aponta para a deficiência nos cursos de formação inicial. Alguns professores argumentam que não fazem atividades experimentais por não dispor de tempo acarretando em aulas conteudistas baseadas na relação teoria- exercício-teoria.

Entende-se que esta busca por novas formas de aprendizagem deve fazer parte do cotidiano dos professores. Quando se chega à sala de aula, principalmente à noite, encontramos alunos cansados e sem ânimo para trocarem as experiências vividas com as que a escola tem a oferecer. Isto tem de ser levado em conta e não se podem levar para as aulas textos longos e sem conexão com a realidade dos alunos, não se importando com a beleza que podemos mostrar através dos conteúdos que nos são sugeridos.

Além disso, é observado no discurso pedagógico, que o professor deve estar consciente da necessidade de estar com suas aulas sempre bem planejadas. Este planejamento irá deixálo com mais segurança e em condições de debater com seus alunos sobre o conteúdo desenvolvido, buscando um engajamento de todos na busca do conhecimento. 
Para que o ensino-aprendizagem da Matemática se torne dinâmico e interessante ao aluno, despertando um interesse pelo estudo, proporcionando uma interação com o professor e seus colegas na busca do melhor entendimento e compreensão dos princípios matemáticos, o professor deve adotar novas metodologias. Os estudantes precisam de estímulos, situações que envolvam aplicações matemáticas no cotidiano devem ser introduzidas no planejamento do professor, pois irão mostrar ao aluno que os conteúdos estudados em sala possuem importância para as várias classes da sociedade (VITTI, 1999).

Percebe-se que a formação do professor também deixa muito a desejar. O educador não está preparado para os novos desafios. Muita coisa mudou, mas não o suficiente. Existem dificuldades para colocar em prática as novas concepções e os novos modelos. É preciso estar aberto às novidades e procurar diferentes métodos de trabalho, partindo de uma análise individual e coletiva das práticas (FREIRE, 1998).

Então o preparo e o planejamento das aulas feitos com antecedência associado as aulas dinâmicas e conhecendo nossa realidade alvo, contribui para que possamos prender a atenção dos alunos, estabelecendo a relação professor-aluno estimulada pelo desejo de saber. Utilizando novas metodologias e novas formas de buscar o ensino-aprendizagem, os resultados serão alcançados, tendo como principal alvo a formação de cidadãos competentes e capazes de integrar e contribuir para um novo modelo de sociedade.

\section{Conclusões}

A partir da problematização apresentada, a matemática e o desinteresse dos alunos na escola nos dias atuais, realizado um diagnóstico, a ousadia, a criatividade e a experimentação, as mudanças impulsionam a perspectiva de competência dos alunos. Como o professor é o orientador desse processo ensino-aprendizagem, deve sempre renovar sua metodologia. Para isso ocorrer, antes temos que fazer um autoavaliação, enquanto profissional. Não se deve considerar uma avaliação que considere o aluno como um produto.

O professor da matéria dá aula, explica a matemática para os alunos, normalmente é assim. Onde na grande parte dos professores fazem isso para o aluno, onde o ideal seria fazer com o aluno. Desse modo que trabalham, em forma de presente, os estudantes acabam rejeitando essa matemática. Concordando com o fio condutor de Parra (1996) e Bock (1999), que com outras palavras, afirmam que se deve procurar a metodologia mais adequada, e que a motivação é o aspecto dinâmico da ação, é o que leva a pessoa a agir, ou melhor, a fazer ação do seu objetivo. A aprendizagem necessita de um sentido para o aluno. Com o incentivo, a 
motivação, a autoconfiança, desenvolvendo sua dependência, autonomia e o raciocínio matemático.

Ao resolver questões de matemática e não ser apenas meros respondedores de questões, a metodologia precisa ser bem fundamentado. Pois no momento em que vivenciamos, as mudanças na educação, os professores apresentam a mesma postura em sala de aula, mudando apenas o discurso, e a prática permanece a mesma. Mas existe outro problema na escola, o autoritarismo, que às vezes impede os alunos de se expressarem.

A matemática como para muitos é considerada uma matéria difícil, em alguns casos, os professores incentivam a dificuldade, tornando-o excitante e menos difícil de ser compreendido. Atualmente ainda há professores que trabalham apenas com aulas expositivas, transferindo apenas o conteúdo dos livros para o quadro. Concordando-se plenamente com Faundez quando se refere que o processo educacional é para criar uma nova pedagogia, democracia, uma nova sociedade, sendo preciso estar observando para que este processo se faça de uma participação crítica, criativa, livre e ativa.

Como a pesquisa foi realizada com 15 alunos, escolhidos aleatoriamente, não se dá para generalizar o quanto a matemática é difícil ou fácil, pois o público alvo foi limitado e aleatório, possa ser que dos alunos entrevistados, a maioria tenha afinidade com a matemática. Porém essa problematização fica para futuros fica para futuros estudos. O que se torna perceptível é a metodologia, nos quais os alunos frisaram afirmar que aulas tradicionais tornam-se cansativas, monótonas, além do desinteresse pela matéria.

Um dos desinteresses pela matemática está na formação dos professores que tem como base os pressupostos do ensino tradicional. Como os próprios alunos indagaram a aula dinâmica, interativa, atrai a atenção, levando o aluno a sanar as dificuldades que surgirem no decorrer da aprendizagem, gerando maior interesse pela disciplina.

Com essa falta de preparo, por parte dos professores, de trabalhar em forma dinâmica, os alunos se acomodando e desanimam em relação às mudanças, continuando suas aulas tradicionais com piloto, livro e exercício fora da realidade do aluno, contribuindo sem dúvida, para considerarem a matéria muito difícil.

O modo como se leciona e a metodologia centralizada na habilidade que incentiva uma aprendizagem permanente proporciona aos alunos aprender a aprender, aprender a pensar e aprender a construir seu próprio conhecimento. As atividades devem ser eticamente corretas, onde desejem uma aprendizagem compartilhada, cooperativa e solidária na resolução de problemas. Tanto os alunos como o professor precisam reconhecer que o complicado faz parte do 
processo de aprendizagem e que há necessidade de estar aberto para mudanças e não se acomodar refletindo sobre a prática cotidiana. Não há professor sem aluno, e aluno sem professor. Quem ensina aprende a ensinar e quem aprende ensina ao aprender.

Todos nós sentimos necessidade de sermos desafiados, e o professor que propiciar isto ao estudante, dará oportunidade de se desenvolverem, facilitando uma tarefa e, a rejeição na disciplina será bem menor.

A matemática poderá proporcionar ao aluno a capacidade de leitura do mundo, permitindo-os interpretar, analisar, criticar e propor possibilidades de mudanças. Então o professor que estimula a autonomia do aluno, possibilita a capacidade de formar cidadãos conscientes e preparados para agir e mudar a sociedade.

\section{Referências}

AQUINO, J. G. A relação professor-aluno: do pedagógico ao institucional. São Paulo: Summus, 1996.

ARAÚJO, J. L.; BORBA, M. C. Construindo pesquisas coletivamente em Educação Matemática. In: ARAÚJO, Jussara de Loiola; BORBA, Marcelo de Carvalho. Pesquisa Qualitativa em Educação Matemática. Belo Horizonte: Autêntica, 2004.

BOCK, A. M. B. (org). Psicologias: uma introdução ao estudo de Psicologia. 13. ed. São Paulo: Saraiva, 1999.

BORUCHOVITCH, E.; BZUNECK, J. A. (orgs.). A motivação do aluno: contribuições da psicologia contemporânea. 3. ed. Petrópolis: Vozes, 2004.

BRASIL. Parâmetros curriculares nacionais: matemática. 3. ed. Brasília: MEC/SEF, 2001.

DANTE, L. R. Didática da resolução de problemas de matemática. São Paulo: Ática, 1989.

D'AMBROSIO, U. Da realidade à Ação: Reflexões sobre Educação (e) Matemática.

Campinas. SP: Summus/UNICAMP, 1986.

DOCKRELL, J. MCSHANE, J. Crianças com dificuldades de aprendizagem: uma abordagem cognitiva. Trad. Negrera, A. Porto Alegre: Artes Médicas Sul, 2000.

FREIRE, P. Pedagogia da autonomia: saberes necessários à prática educativa. 9. ed. São Paulo: Paz e Terra, 1998.

GODOY, A. S., Introdução à pesquisa qualitativa e suas possibilidades, In Revista de Administração de Empresas, v. 35, n. 2, mar./abr. 1995a, p. 57-63. Pesquisa qualitativa. - tipos fundamentais, In Revista de Administração de Empresas, v. 35, n. 3, Mai./Jun., p. 20-29, 1995 b. 
LIMA, E. S. Desenvolvimento e aprendizagem na escola: Aspectos Culturais, Neurológicos e psicológicos. São Paulo: GEDH; série "Separatas", 1997.

LOPES, M. G. Jogos na educação: criar, fazer e jogar. 6. ed. São Paulo: Cortez, 2005.

LORENZATO, S. Para aprender matemática. Campinas, SP: Autores Associados, (Coleção Formação de Professores). 2006.

MIGUEL, A.; MIORIM, M. Â. História na Educação Matemática: Propostas e Desafios. 2. ed. Belo Horizonte: Autêntica Editora, 2011.

PARRA, C.; SAIZ, I. Didática da Matemática: Reflexões Psicopedagógica. Porto Alegre, Artmed (Artes Médicas). 1996. 258 p.

SADOVSKY, P. Falta Fundamentação Didática no Ensino da Matemática. Nova Escola. São Paulo, ed. Abril, jan./fev. 2007.

SANTOS, G. $\quad$ Evasão. $2003 . \quad 20$ Disponível em <http://www.ebah.com.br/content/ABAAAAzdkAK/evasao>. Acesso em: 6 de agosto de 2014.

VITTI, C. M. Matemática com prazer, a partir da história e da geometria. 2. ed. Piracicaba São Paulo. Editora UNIMEP. 1999. 103 p. 